\title{
Time-lapse electrical resistivity investigation of seawater intrusion in coastal aquifer of Ibeno, Southeastern Nigeria
}

\author{
Iniemem J. Inim ${ }^{1}$ (1) $\cdot$ Ndifreke I. Udosen ${ }^{2} \cdot$ Moshood N. Tijani ${ }^{3} \cdot$ Uduak E. Affiah ${ }^{1,4} \cdot$ Nyakno J. George $^{2}$
}

Received: 18 July 2019 / Accepted: 13 October 2020 / Published online: 31 October 2020

(c) The Author(s) 2020

\begin{abstract}
Saltwater intrusion, erosion, and periodic flooding during severe storms are some of the critical problems bedeviling the precarious coastal environment of Nigeria. A time-lapse study aimed at monitoring the dynamics of saltwater intrusion within the coastland surrounding Ibeno, southeastern Nigeria is presented. Three (3) vertical electrical soundings (VES) and four time-lapse electrical resistivity tomography (ERT) profiles with minimum and maximum electrode spacing of $5 \mathrm{~m}$ and $40 \mathrm{~m}$ and profile lengths of $120 \mathrm{~m}$ and $150 \mathrm{~m}$ respectively were acquired in 2016 and 2017 using the Wenner and Schlumberger arrays. Data acquired from the field surveys were modeled with WINRESIST and RES2DINV software to generate $1 \mathrm{D}$ and 2D resistivity images of the subsurface. The VES results with a maximum survey length of $A B=300 \mathrm{~m}$ revealed a four-layer KH curve. The 2D geo-electrical sections delineated contrast between the high resistivity values obtained for the saturated freshwater zones and the low resistivity values obtained for the saturated saltwater zone. Expectedly, the intrusion was dominant nearer the coastline than inland. The salinity changes are believed to have been caused by both incremental tides passing through highly porous materials in the active-salinity change area and over-pumping of groundwater. The timelapse resistivity measurements showed significant, active lateral salinity changes rapidly intruding the freshwater aquifers. The study demonstrates the application of time-lapse 2D ERT and vertical electrical sounding in identifying the spatial and temporal changes of saltwater intrusion in the coastal aquifer.
\end{abstract}

Keywords Saltwater intrusion - Vertical electrical sounding · Electrical resistivity tomography $\cdot$ Coastal aquifers $\cdot$ Timelapse ERT · Ibeno

\section{Introduction}

The economic significance of coastal regions and its consequent rapid increase in population cannot be overemphasized as major cities of the world are situated there. The need for their development has led to increasing emphasis on developing available resources including groundwater (George et al. 2014). The southern part of Akwa Ibom State

Iniemem J. Inim

iniememinim@yahoo.com

1 Department of Geology, Akwa Ibom State University, Mkpat Enin, Nigeria

2 Department of Physics (Geophysics Research Group), Akwa Ibom State University, Mkpat Enin, Nigeria

3 Department of Geology, University of Ibadan, Ibadan, Nigeria

4 School of Geographical and Earth Science, University of Glasgow, Glasgow, Scotland, UK in Nigeria, which harbors more than $30 \%$ of Nigeria's crude oil resources, is presently experiencing an increase in human population and industrialization (Edet and Okereke 2001a, b). The availability of groundwater resources in this area has never been in doubt, because geologically, the study area comprises highly productive aquifers (Edet 2017). The challenge, however, has been that of poor groundwater quality due to increase in rate of potable water abstraction and uncontrolled land-use practices among others. These practices have negative impact on groundwater quality, and one of such is saltwater intrusion (Edet and Okereke 2001a, b; Udom et al. 1999, 2002).

Saltwater intrusion is a global environmental phenomenon that affects the chemical composition of the coastal groundwater and this may be more critical in the near future due to the increasing sea level rise associated with climate change (Antonellini et al. 2008). Furthermore, growing water demands and manipulation of natural hydrologic systems have led to saltwater intrusion being considered a 
significant future threat to coastal freshwater resources globally (Kinzelbach et al. 2003; Barlow and Reichard 2010; Werner et al. 2013).

Delineation of marine intrusion in coastal aquifers has traditionally relied upon observation wells and collection of water samples (George et al. 2015; Mahjoub et al. 2017). This study area is not an exception. Several studies on saltwater intrusion or contamination in the southern Akwa Ibom area mostly deal with water quality and geochemical assessment (Edet and Okereke 2011a, b; Inim et al. 2017; Edet 2017; Affiah et al. 2018). Measurements made in wells provide point data, which may fail to capture the spatial complexity in subsurface conditions. Improving the spatial coverage with additional wells will attract additional cost. Time-lapse geo-electrical surveying attempts to detect variations in the electrical properties of the subsurface with time, introducing an additional dimension into the data collection (Giordano et al. 2017; Loke et al. 2017; Du et al. 2018; Shin et al. 2019). This technique can be carried out over short time periods (e.g., several days with readings taken every few hours) and has been used for the evaluation of the migration of contamination plumes (Chambers et al. 2004; Radulescu et al. 2007), early detection of dam failure (Shin et al. 2019) the detection and monitoring of concentration of conductive contaminants within aquifers (Chambers et al. 2004; Cassiani et al. 2006; Oldenborger et al. 2007), the quantification of superficial water infiltration rates into the subsurface (Barker and Moore 1998), and tracer test monitoring (Monego et al. 2010; Ward et al. 2010). Long-term time-lapse resistivity surveys have been applied in the monitoring of seasonal variations on seepage rates (Johansson and Dahlin 1996; Sjödahl et al. 2008) and the monitoring of salinity within aquifers in coastal areas (Leroux and Dahlin 2006; de Franco et al. 2009; Ogilvy et al. 2009).

Coastal regions in Nigeria are affected by saltwater intrusion. Although studies have been carried out in other parts of the country to investigate the extent of the problem, this study is the first in Ibeno area, a major oil-producing area in Nigeria. There has been very limited research on the problem of saltwater intrusion in the region, but the problem is expected to worsen in the future as a result of coastal erosion, climate changes, increase in sea-level rise, and increase in human population (with a corresponding increase in the demand for potable water). A deeper knowledge of the problem is important to help the government plan for the future.

Saline water intrusion does occur naturally but mostly becomes a problem when freshwater is pumped from the aquifer. Pumping of freshwater reduces the aquifer's hydraulic head. This causes reduction in the elevation of the water table and enables the seawater to move inland. Another problem associated with overexploitation of groundwater is upconing, and this occurs when saltwater from the surrounding underlying saltwater wedges are drawn up a well, causing a contamination of the freshwater resources. Increases in sealevel rise, extreme weather events, reduced natural recharge from rainfall, can all cause an inland shift of the saltwater-freshwater interface, contaminating freshwater sources and aggravating the problem of saltwater intrusion. In the study area, the occupants use wells to pump freshwater to the surface, and this aggravates the problem of salt water intrusion. As it so happens in this densely populated locality, more freshwater is typically withdrawn than the aquifer can supply, leading to pumping out of saline water, and a consequent abandonment of the well.

According to IPCC (2007), climate change will lead to increase in sea level rise, changing precipitation patterns, extreme weather events, and coastal erosion within the coastal areas. This will make water supplies even more vulnerable to saline water contamination especially for people living along the coastline. IPCC (2007) has predicted that by year 2100 , the sea will rise to values ranging from 18 to $59 \mathrm{~cm}$ globally. As alarming as such predictions are, Rahmstorf (2010) has predicted even greater levels of sea-rise (values twice more than that predicted by IPCC.) This rise will definitely lead to increases in the rate of seawater intrusion along the coastline and will affect infrastructure and residential areas in areas close to the coastline. This study aimed at assessing seawater intrusion using the time-lapse electrical resistivity approach to understand the spatial and temporal changes for better planning and management of groundwater resources. Data acquired from the field surveys were modeled with WINRESIST and RES2DINV software to generate $1 \mathrm{D}$ and $2 \mathrm{D}$ resistivity images of the subsurface.

\section{Setting of study area}

The study area (Ibeno) which is located in the coastal area of Akwa Ibom, southeastern Nigeria, lies between Latitudes $4^{\circ} 30^{\prime} \mathrm{N}$ and $4^{\circ} 36^{\prime} \mathrm{N}$ and Longitudes $7^{\circ} 48^{\prime} \mathrm{E}$ and $8^{\circ} 18^{\prime} \mathrm{E}$. The area is drained mainly by Imo River, Kwa Iboe River, and Cross River together with their tributaries (Fig. 1).

The area is characterized mostly by flat lying sandy deposits, while the main landforms are mangrove swamps and floodplains with recent alluvial accumulations, beach ridges, and mangrove mudflats (Petters 1989). The area experiences two seasons: wet season (April-October) and dry season (November-March), while the average annual rainfall is about $3000 \mathrm{~mm}$ characterized by humid tropical climate. Geologically, the study area is underlain by Recent to Tertiary sediments belonging to the Benin Formation of Niger Delta. The grain size of these sediments ranges from coarse to fine in texture and are poorly sorted. They have great thickness and minor intercalations of clay, silts, and sandstones with alternating sequence which builds up multiple aquifer systems with various thicknesses. The major 


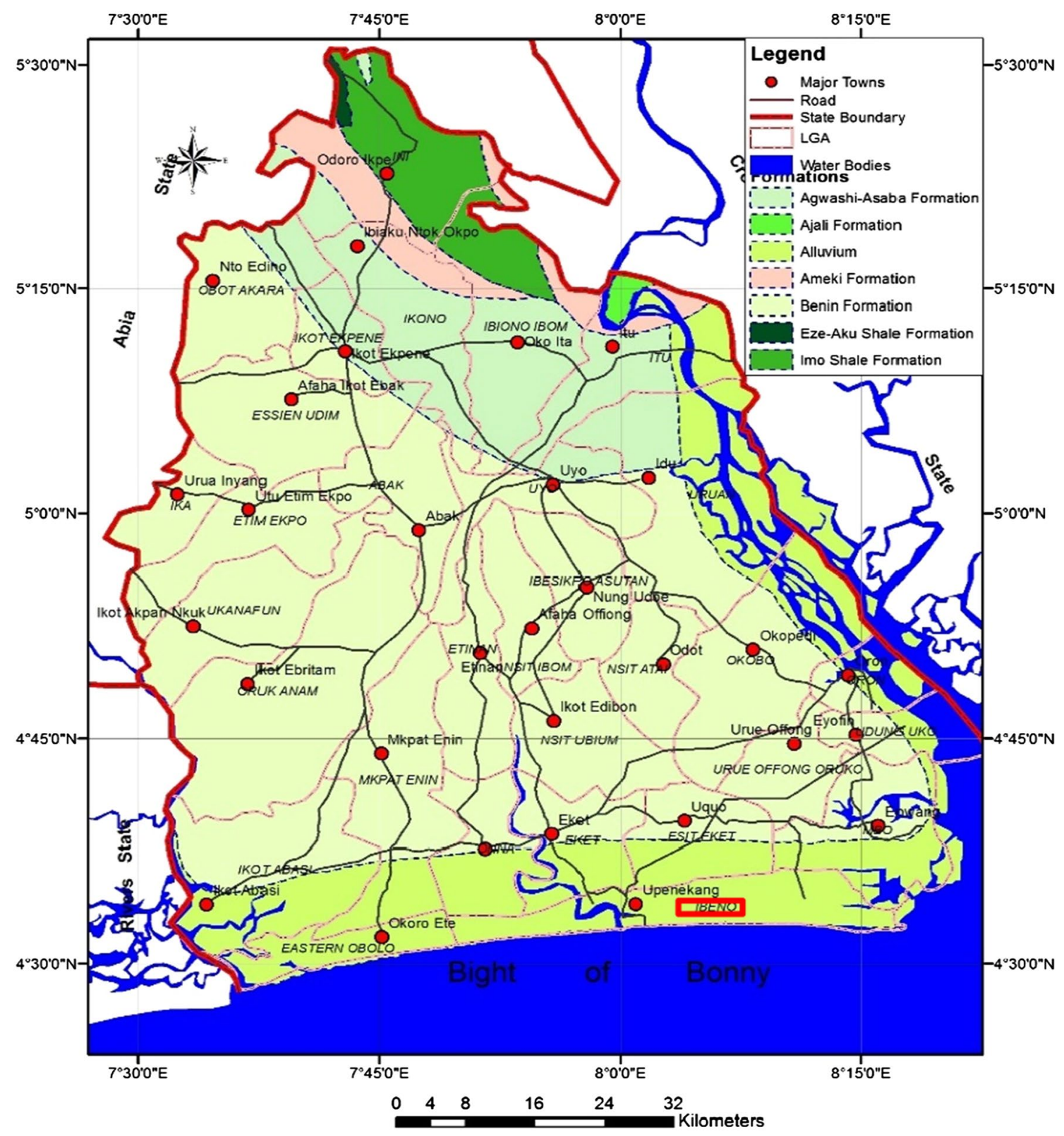

Fig. 1 Geologic map of the study area

hydro-stratigraphic units within the study area are the upper sandy aquifer comprising recent alluvial material and the coastal plains of Benin Formation (Esu et al. 1999). These Coastal plain sands are mostly made up of unconsolidated sands and gravelly sands with clay intercalations, while the Alluvium comprises gravels, lateritic sands, fine to medium grained, and carbonaceous sand (Esu et al. 1999). The upper sand aquifer has the following characteristics: thickness 20-200 m, saturated thickness of aquifer 39-100 m, static water level $1-55 \mathrm{~m}$, yield $316-530 \mathrm{~m}^{3} / \mathrm{d}$, transmissivity $200-8300 \mathrm{~m}^{2} / \mathrm{d}$, hydraulic conductivity $2-28 \mathrm{~m} / \mathrm{d}$, drawdown $1.2-42.5 \mathrm{~m}$, and storage coefficient $0.10-0.30$ (Esu et al. 1999).

\section{Materials and methods}

An ABEM terameter was used to collect vertical electrical sounding (VES) and time-lapse electrical resistivity tomography (ERT) data. The VES method, employing Schlumberger electrode configuration, was used to obtain three profile lines. The maximum current electrode separation was $100 \mathrm{~m}$ for VES line 1, $150 \mathrm{~m}$ for VES line 2 and VES line 3. 
The WINRESIST software was used to generate logarithmic curves of apparent resistivity against $\mathrm{AB} / 2$.

Data acquired from the VES field survey were modeled with WinResist software to generate VES resistivity images of the cross section of each profile line. The ERT survey was carried out along four profile lines: ERT Line 1, ERT Line 2, ERT Line 3, and ERT Line 4 (Fig. 2). Along ERT Line 1 and ERT Line 2, the profile length was $120 \mathrm{~m}$. Along ERT Line 3 , the profile length was $135 \mathrm{~m}$, and along ERT Line 4, the profile length was $150 \mathrm{~m}$. Minimum and maximum electrode spacing of $5 \mathrm{~m}$ and $30 \mathrm{~m}$ was used in the ERT surveys. The Wenner configuration was used due to its high sensitivity to horizontal structures, low sensitivity to geological noise, and strong signal strength which is useful in areas with high background noise. Data acquired from the field survey were modeled with RES2DINV software from Geotomo to generate $2 \mathrm{D}$ resistivity images of the cross section of each profile line. Time-lapse ERT surveys were undertaken in March 2017 (12 months after the initial survey in 2016).

\section{Results and discussion}

\section{VES and ERT survey}

Qualitatively, the VES curves revealed a $\mathrm{KH}$ type for which $\rho 1<\rho 2>\rho 3<\rho 4$, while quantitatively (interpreted using existing borehole lithology log within the study area) (Fig. 4b), it revealed (Fig. 3, 4a), from top to bottom the following layers; lateritic top soil with resistivity and thickness ranging from (180-280 $\Omega \mathrm{m})$ and $(0.5-1 \mathrm{~m})$, respectively, freshwater sand with resistivity and thickness ranging from (340-1667 $\Omega \mathrm{m})$ and (1-6 m), respectively, and saline sand with resistivity and thickness ranging from (14-112 $\Omega \mathrm{m})$ and (4-13 m), respectively. Underlying the saline sand is clayey sand with resistivity values ranging from 560-2500 $\Omega \mathrm{m}$ with infinite depth.

The four ERT sections delineated contrasts between the high resistivity values obtained from the saturated freshwater zones and the low resistivity values obtained from the

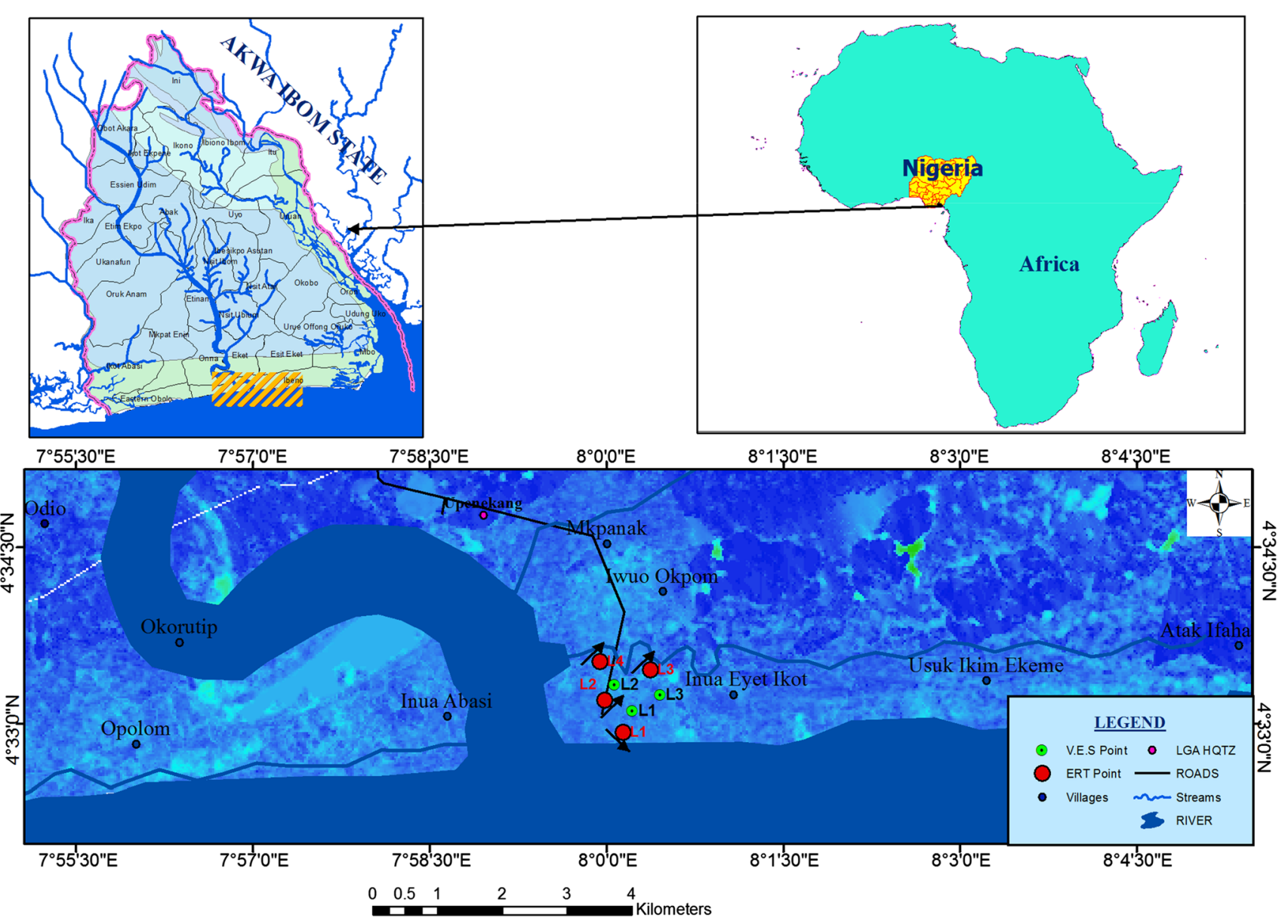

Fig. 2 Map of the study area showing survey lines 
(a)

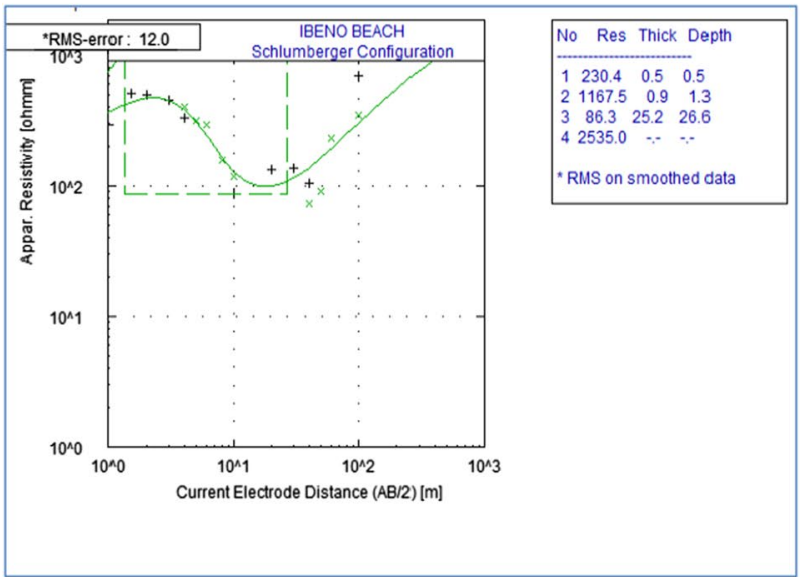

(b)

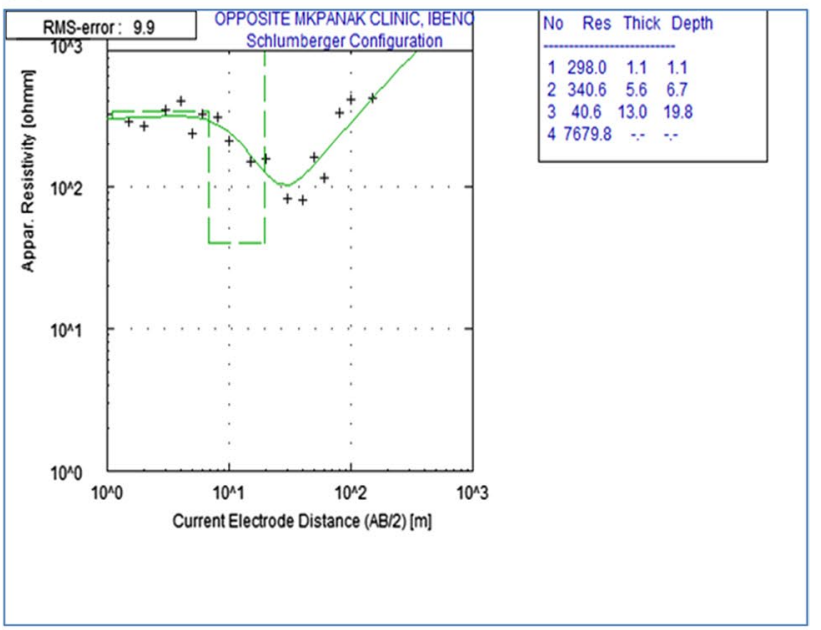

(c)

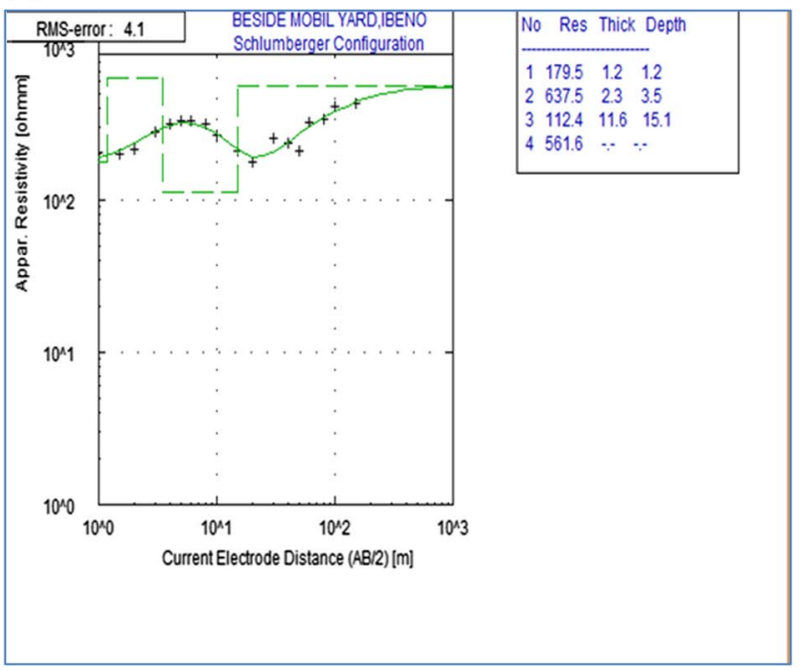

Fig. 3 Resistivity profiles generated from vertical electrical sounding data. a VES 1, b VES 2, c VES 3 (a)

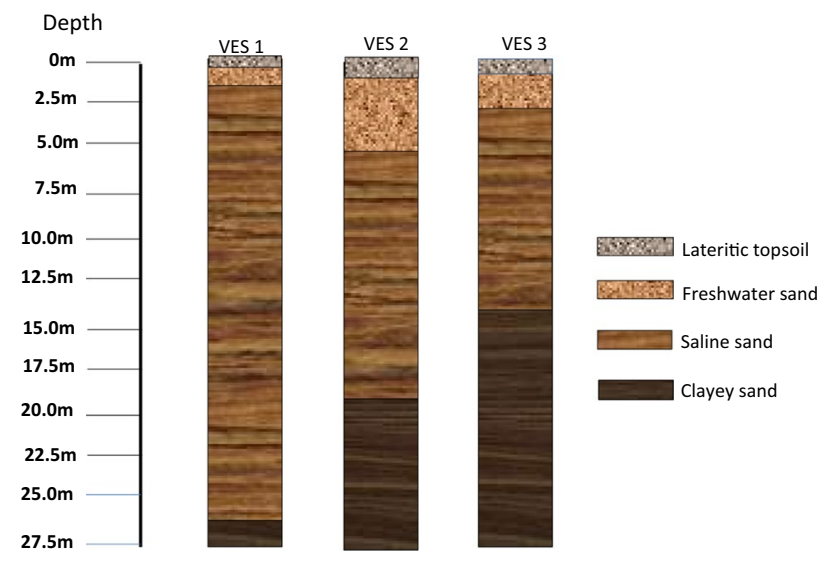

(b)

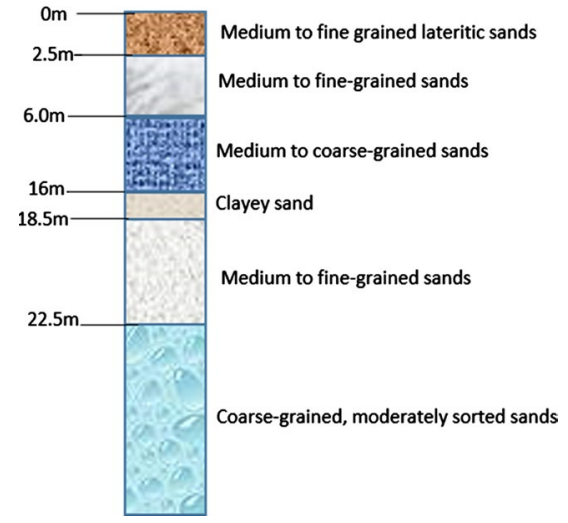

Fig. 4 a Qualitative interpretation of VES model obtained, b borehole lithology logs

saturated saltwater zone and revealed three distinct resistivity zones. The first ERT profile, ERT1, acquired in 2016 which runs NW-SE; upland to coastline (Fig. 5a) shows a top layer of high resistivity ranging from 140 to $300 \Omega \mathrm{m}$ with approximately $4 \mathrm{~m}$ vertical extension which corresponds to unconsolidated sand (top soil). This is underlain by a layer of low to medium resistivity (10-100 $\Omega$ m) with a depth range of 4-18 $\mathrm{m}$. This second layer corresponds to the sandy aquifer which is intruded by saline water. Underlying this aquifer is another higher resistivity zone (300-800 $\Omega \mathrm{m})$ which represents the consolidated clayey sand formation.

The second ERT profile, ERT2, acquired in 2016 runs in SW-NE direction (Fig. 5b) and reveals a medium resistivity zone on the top that corresponds to the sandy clay unit. The region of low resistivity values (below $153 \Omega \mathrm{m}$ ) underlying the sandy clay unit of the profile corresponds to the sandy aquifer intruded by saline water, and it extends from depth $8 \mathrm{~m}$ to more than $20 \mathrm{~m}$. The sandy aquifer intruded by saline water is underlain by a high resistivity layer which corresponds to a sand pocket with resistivity values above 390 $\Omega \mathrm{m}$ with depth ranging from $19 \mathrm{~m}$ to more than $30 \mathrm{~m}$.

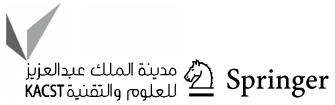


(a)

NW

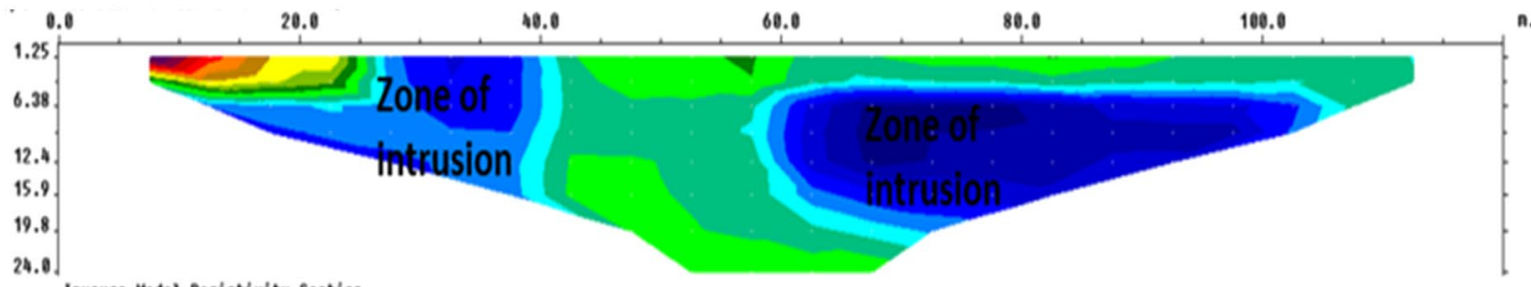

(b)

Inverse nodel Resistivity Section

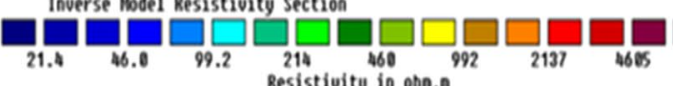

Unit electrode spacing $5.00 \mathrm{n}$.

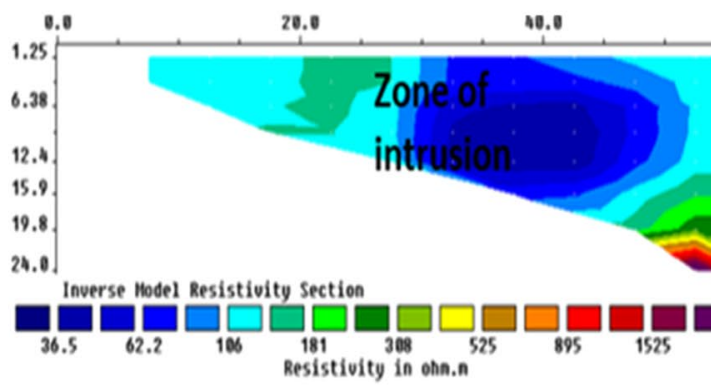

60.

80.0

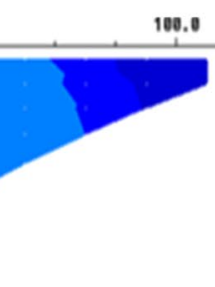

100.

(c)

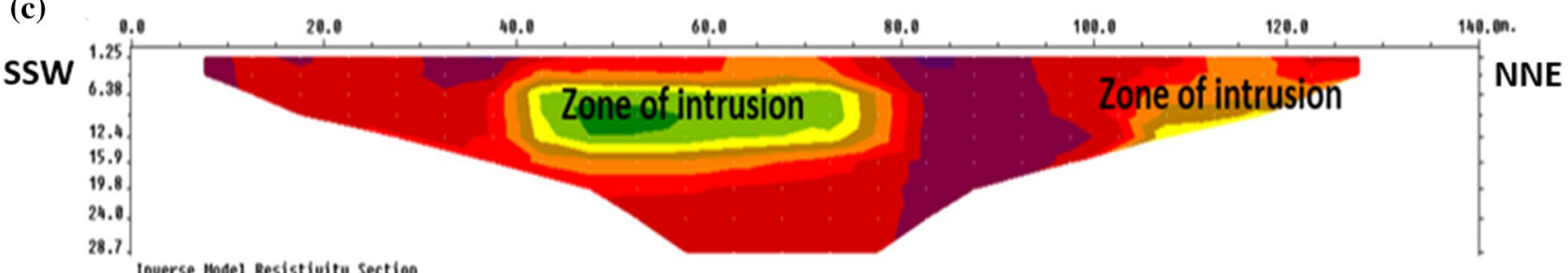

Unit electrode spacing $5.00 \mathrm{n}$.

Inverse Model Resistivity section

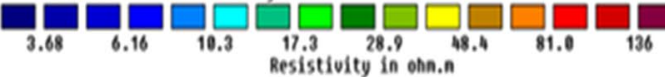

Unit electrode spacing s.00 n.

(d)

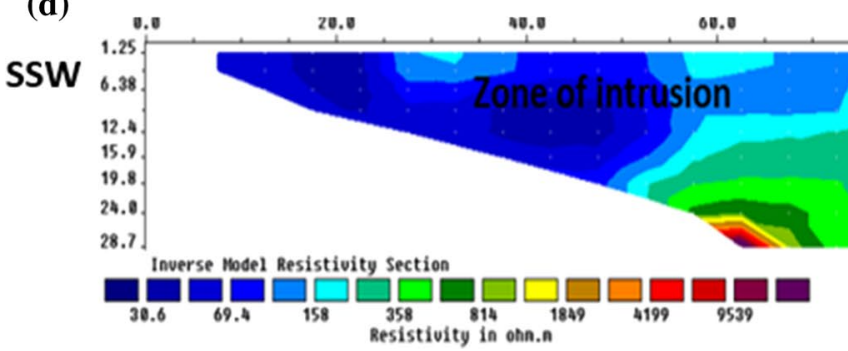

Unit electrode spacing $5.00 \mathrm{n}$.

Fig. 5 ERT profiles obtained in 2016 a ERT 1 profile, $\mathbf{b}$ ERT 2 profile, $\mathbf{c}$ ERT 3 profile, $\mathbf{d}$ ERT 4 profile

The third ERT profile, ERT3, acquired in 2016 runs in SSW-NNE direction (Fig. 5c). The first zone with resistivity values ranging from 80 to $100 \Omega \mathrm{m}$ and depth of $2 \mathrm{~m}$ represents the top soil. Underlying it is the saline water intruded sandy aquifer with resistivity values ranging between 17 and $50 \Omega \mathrm{m}$ and depth range of $2-25 \mathrm{~m}$. The third zone representing consolidated clayey sand shows resistivity values greater than $200 \Omega \mathrm{m}$ at depths ranging from 20 to $30 \mathrm{~m}$.
The fourth ERT profile, ERT 4, acquired in 2016 profile runs in SSW-NNE direction (Fig. 5d). The first zone with resistivity values ranging from 150 to $300 \Omega \mathrm{m}$ and depth of $2 \mathrm{~m}$ represents the top soil. Underlying it is the saline water intruded sandy aquifer with resistivity values ranging between 30 and $150 \Omega \mathrm{m}$ and depth range of 2-20 m. The third zone shows resistivity values ranging between 800 and $1500 \Omega \mathrm{m}$ with depth range of $20-30 \mathrm{~m}$ representing consolidated clayey sand. 


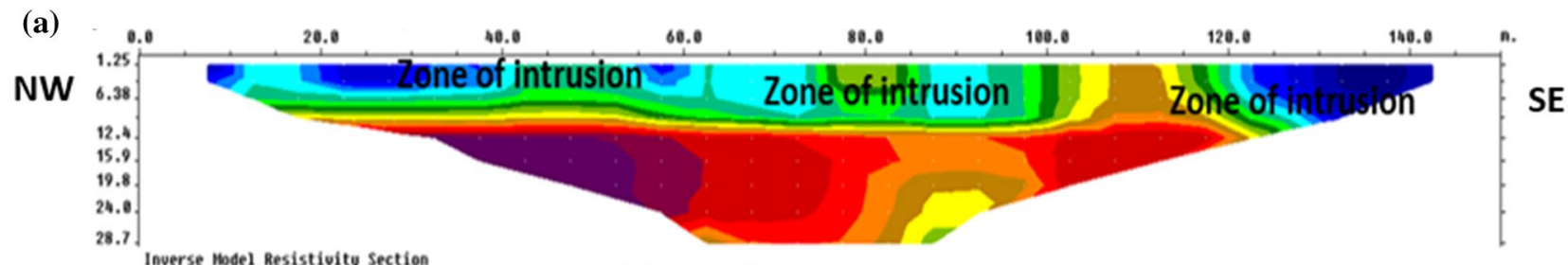

(b)

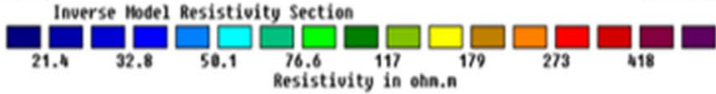

Unit electrode spacing $5.00 \mathrm{n}$.

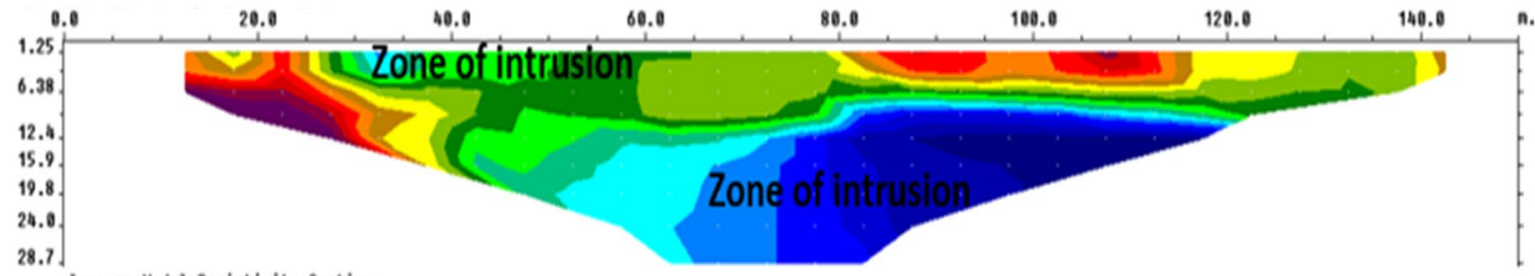

(c)

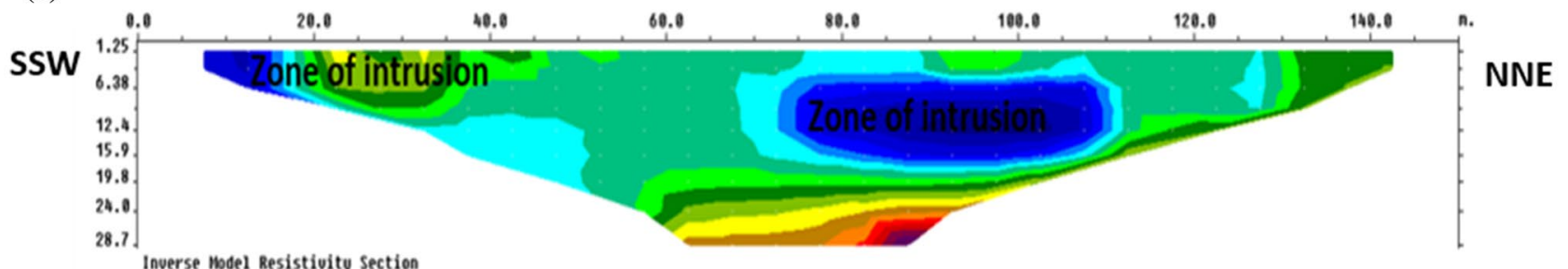

Inverse Model Resistivity Section

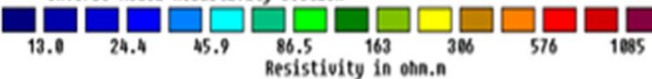

Unit electrode spacing $5.00 \mathrm{n}$.

(d)

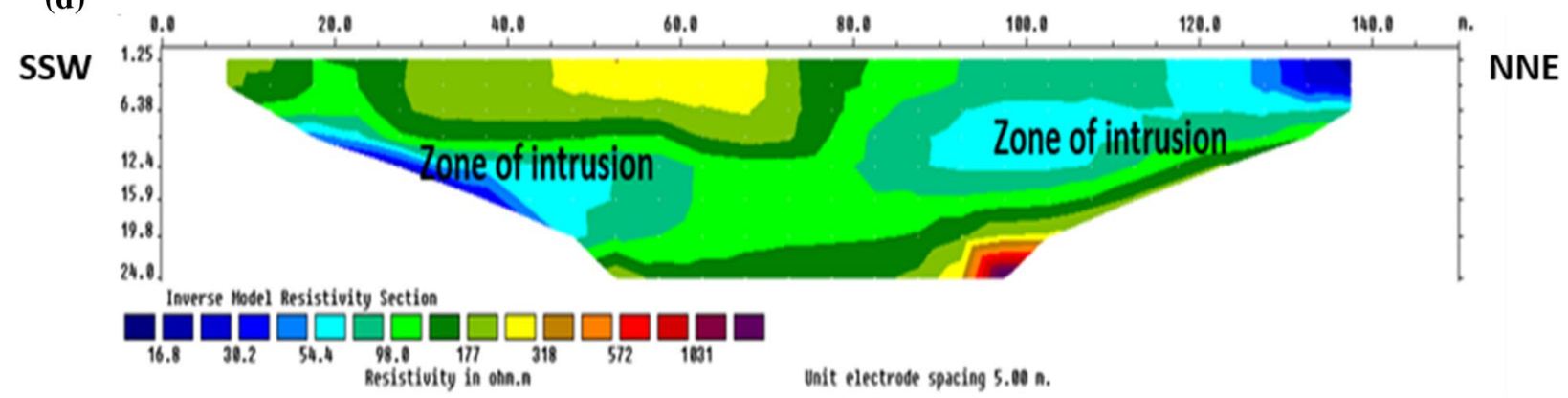

Fig. 6 ERT profiles obtained in 2017 a ERT 1 profile, b ERT 2 profile, $\mathbf{c}$ ERT 3 profile, d ERT 4 profile

In 2017, ERT data were again acquired at the exact locations and profile lines as those previously obtained in 2016 (see Fig. 6a-d). This was to enable the determination of the extent of saline intrusion.

Figures 5 and 6 show that the saturated freshwater zones are denoted with high resistivity values. The high resistivity values denote the near surface unsaturated zone, which decreases gradually. The reduced resistivity values indicate the presence of saltwater at depths between 0.5 and $20 \mathrm{~m}$
(Figs. 5,6). The saltwater-freshwater interface appears to occur at depths as shallow as $10 \mathrm{~m}$, and since it is rarely a sharp boundary, the interface does extend on some of the profiles downwards to depths as large as $18 \mathrm{~m}$ (e.g., Fig. 6c). It can be seen that the boundary between the freshwater and the saline water is not static, but transits seasonally depending on climatic conditions. This interface, as obtained in this work (see Figs. 5,6) is not a sharp boundary, but a gradual zone of transition (otherwise called zone of dispersion) where the salt water mixes with freshwater water. During 
the rainy season, there is a greater supply of freshwater in the study area and consequently, the freshwater-saline water interface shifts towards the sea which is the case in this study area. During such months, the extreme salinity is reduced. On the other hand, during the dry season, there is generally less supply of groundwater, and more salt water shifts inland from the sea.

\section{Time lapse images}

The difference map images were further obtained by subtracting raw resistivity values obtained on the field in March 2017 from raw resistivity values obtained on the field in March 2016, profile line by profile line. The difference values served as input for inversion with RES2DINV to generate the time lapse images shown in Fig. 7. The high resistivity values on the time lapse images indicate greater increase in salt-water intrusion. In other words, the resistivity values obtained in 2016 were lower than those obtained in 2017. The difference between those values would indicate the extent of intrusion.

In the case where the difference between resistivity values obtained in 2017 and 2016 is minimal, the time-lapse or difference images would show low resistivity values (and this would indicate reduced rate of intrusion). Where the difference between resistivity values obtained in 2017 and 2016 is large, the time-lapse or difference images would show large values of resistivity values and this indicates increased rate of intrusion. The latter is the case at the study area.

The results show that the extent of intrusion is increasing with time. The time lapse for the profile lines shows positive resistivity values ranging from $0.112-45 \Omega \mathrm{m}$ with significant higher values inland, which indicates more conductive zones the subsequent year.

The difference map from profile line 1 (ERT1) (Fig. 7a) shows a top layer with resistivity values ranging from 20 to $60 \Omega \mathrm{m}$ with a vertical extension of about $20 \mathrm{~m}$, indicating a large difference between saline intrusion in 2016 and 2017. The large difference in resistivity values indicates that there is high increment in intrusion with time within the top soil between the two consecutive years. This is attributed to anthropogenic factors such as over-pumping (which comes as a result of increase in population with time), climate changes, increase in sea-level rise, and seasonal tidal influence. The second layer has medium resistivity (1.5-20 $\Omega \mathrm{m})$ with a depth range of $1-12 \mathrm{~m}$. These medium values of resistivity within the sandy aquifer zone indicate increased intrusion in 2017 compared to that in 2016, though lesser than that within the top soil.

The difference image from profile line 2 (ERT2) (Fig. 7b) shows a top layer with resistivity ranging from 20 to $40 \Omega \mathrm{m}$ with vertical extension of about $20 \mathrm{~m}$. The difference in the resistivity values indicates greater intrusion between 2016 and 2017 within the top soil. The top soil overlies another layer with medium resistivity (1-20 $\Omega \mathrm{m}$ ) with a depth range of 1-12 m. The medium values of resistivity within the sandy aquifer zone indicate intrusion though lesser than that within the top soil. The difference images shown in Fig. 7 are similar, indicating greater intrusion in 2017 compared to 2016 within the top soil, the sandy aquifer, and the consolidated clayey sand.

The results obtained in this work complements that of Nowroozi et al (1999) who used resistivity imaging to study the extent of saltwater intrusion into the freshwater aquifer in the eastern shore of Virginia and that of Khalil (2006) where resistivity imaging was used to evaluate geo-electric parameters of the aquifer in the Abu Zenima area, West Sinai, Egypt. Yet another work that used resistivity to investigate the extent of saltwater intrusion was that of Choudhury et al. (2001) where resistivity imaging and seismic refraction were used to investigate the extent of intrusion in the alluvial belt of Digha, East India. Similar to our work, geophysics was able to delineate the geo-stratigraphic units and also showed that the saline zone decreased as one moved away from the shore. Safe zones for water exploitation were delineated on the basis of results obtained from geophysics, and unsafe zones not recommended for exploitation were also delineated. Their work also confirmed that geophysics was an extremely useful tool for investigation and delineation of salt water intrusion even when thick clay formations exist. Yet another work that illustrates salt-water intrusion mapping by geoelectrical imaging surveys is Nassir et al. (2000) where the geo-electrical method was used to map the freshwater-saline water boundary in Yan, State of Kedah, northwest Malaysia. The resistivity sections obtained from their work corroborated the results obtained from borehole and geological information gotten from the site. A sampling of some recent work (Giordano et al. 2017; Loke et al. 2017; Du et al. 2018; Shin et al. 2019) also illustrates that the resistivity method is a fast and efficient method with which to map the interface in an area.

The problem of salt water intrusion in the area is expected to worsen due to compounding factors like climate change and consequent increase in sea level rise, overpumping, increase in human population. Past work in the southern Akwa Ibom region focussed on water quality and geochemical assessment (Edet and Okereke 2011a, b; Inim et al. 2017; Edet 2017; Affiah et al. 2018) which only give point data about the given area in question. Though drilling measurements provide point data, they may fail to capture the spatial complexity in subsurface conditions. Drilling methods have been found to be a costly and formidable undertaking. In many cases, expensive and time-consuming pump tests, borehole drills and core analysis are carried out. This led to the search for economical and undemanding methods of quantifying saline water intrusion. A surface geophysical 
(a)

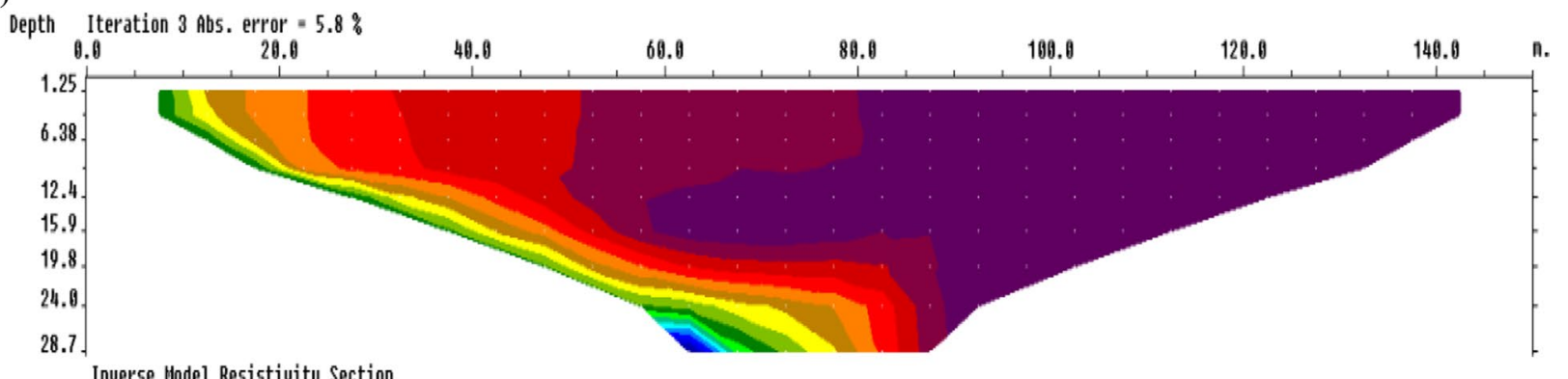

Inverse Hodel Resistivity Section

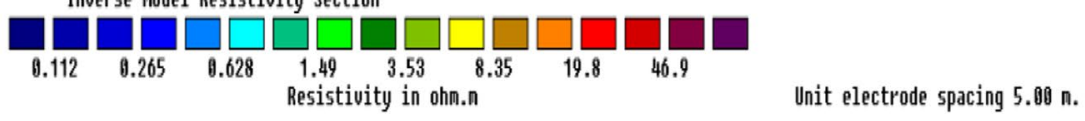

(b)

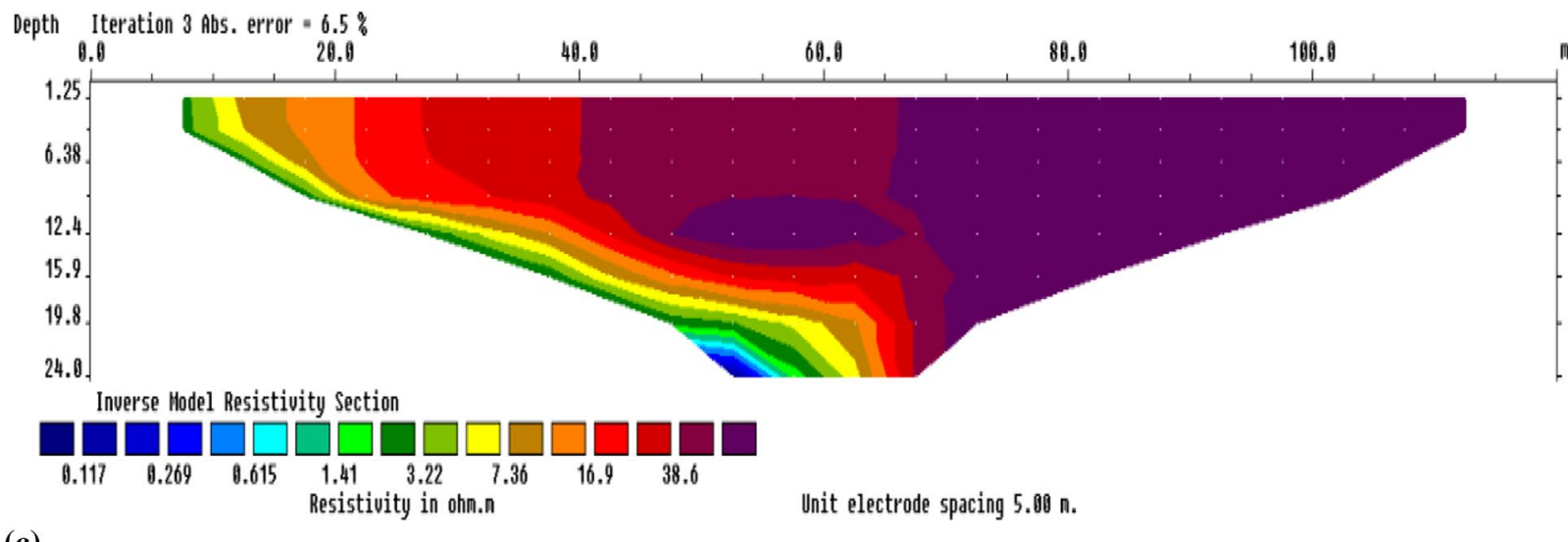

(c)

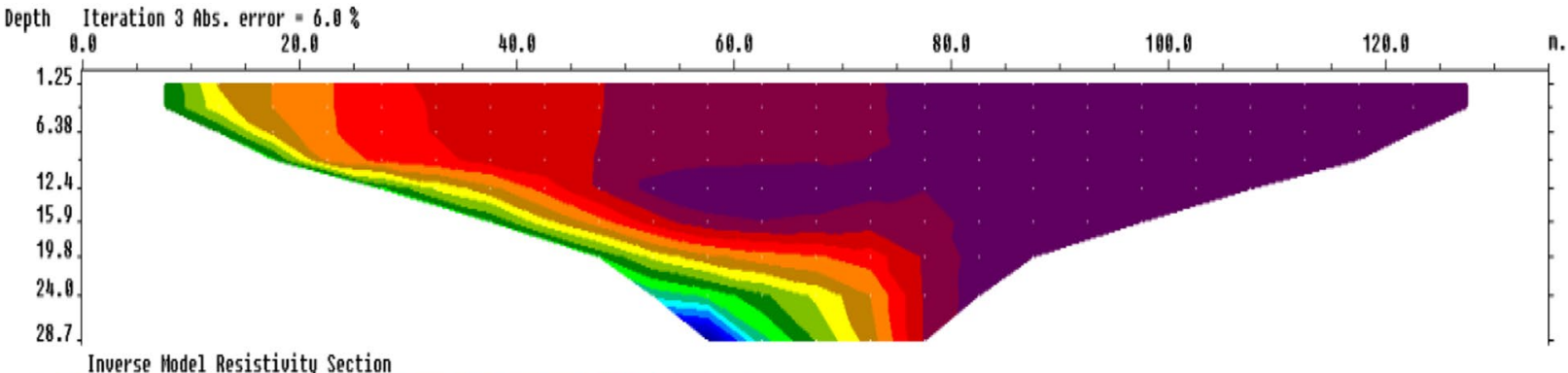

Inverse Hodel Resistivity Section

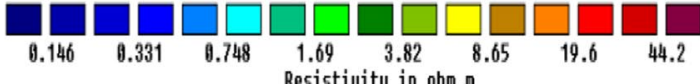

Resistivity in ohm.n Unit electrode spacing $5.00 \mathrm{n}$.

(d)

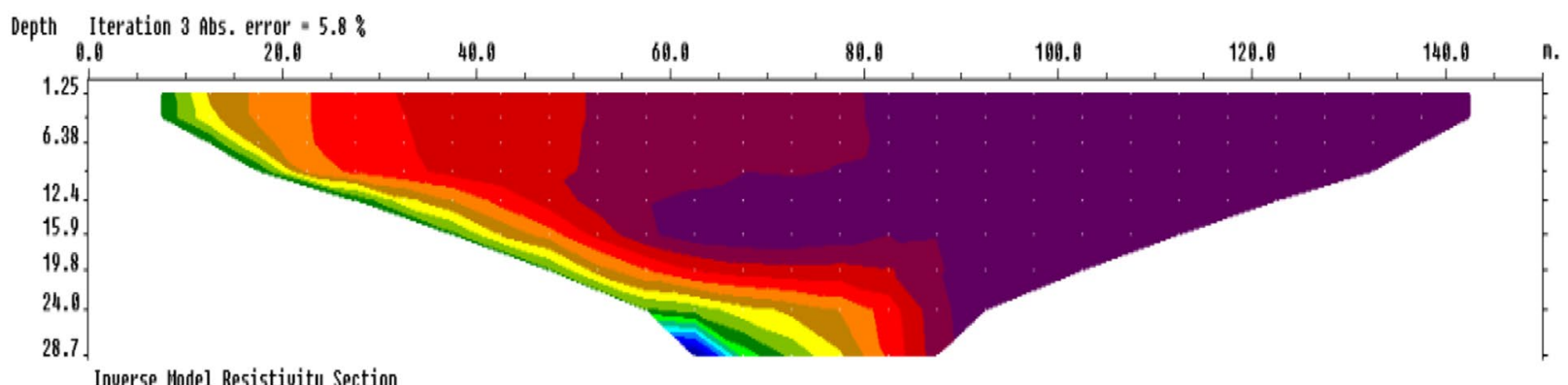

Inverse Hodel Resistivity Section

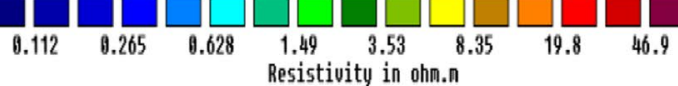

Unit electrode spacing $5.90 \mathrm{n}$.

Fig. 7 Plot of difference (time-lapse) in resistivity values between 2016 and 2017, a TL_ERT1, b TL_ERT2, c TL_ERT3,d TL_ERT4 
method, the resistivity technique, has been found to have the advantage of operational ease, speed, accuracy, noninvasiveness, and inexpensiveness. Time-lapse resistivity surveying attempts to detect variations in the electrical properties of the subsurface with time (Giordano et al. 2017; Loke et al. 2017; Du et al. 2018; Shin et al. 2019). The time-lapse electrical resistivity surveying carried out in the work has been shown in previous work to be a powerful tool for monitoring saline intrusion at different periods in time (Slater et al. 2002; Singha and Gorelick 2005; Cassiani et al. 2006; Leroux and Dahlin 2006; de Franco et al. 2009; Ogilvy et al. 2009).

\section{Conclusion}

In conclusion, time-lapse ERT and VES survey were conducted in Ibeno, South-East of Nigeria, to determine the extent and rate of saltwater intrusion within the coastal aquifer. DC resistivity surveys were carried out in 2016 and 2017 to delineate the lateral and vertical variations of the salt water interface in Ibeno area in South-East of Nigeria. The resistivity surveys were used to detect changes in pore-water resistivity. In areas where low resistivity values $(<2 \Omega \mathrm{m})$ were detected, this indicated the saltwater intrusion into the surrounding groundwater. The VES data generated a geoelectric model having between three and four layers. The 2D imaging of the subsurface variations in the resistivity/ conductivity vividly reflects different lithologies and fluid content. Other than the top soil, the subsurface lithologies consist of prolific sands with intercalations of clayey sands. The silty sands and coarse-sand layers constitute the coastal aquifer units within the area with varying ground water yield as a result of variation in porosity and permeability. Some of the aquifer was contaminated with saline water (lateral encroachment) from tidal influence and/or the increase in groundwater abstraction causing a reversal in the natural groundwater gradients. This work has shown that the salt water has intruded into the freshwater aquifer down to a depth of over $20 \mathrm{~m}$. The time-lapse ERT (2016 and 2017) measurements showed significant, active lateral, and vertical salinity changes rapidly intruding the freshwater aquifers. Area that were previously not intruded are experiencing intrusion while those already intruded are experiencing higher concentration. This increase in intrusion implies a decrement in the amount of potable water for inhabitants of the area (which has led to public health problems) and a continual encroachment and deterioration of the region as a result of saline intrusion.

This work is the first to characterize saline water intrusion along the coastline of Ibeno, a major oil-producing region in Nigeria, with geophysical techniques in order to quantify the extent of saline intrusion in the region rather than with time-consuming and expensive methods such as chemical analysis of groundwater samples, well-logging, profiling of temperature or chloride concentration, which only give point data about the location in question. Results obtained from the geophysical investigations undertaken correspond to those obtained from geochemical analysis of water samples at the site, showing that resistivity imaging is a useful tool for determining the extent of saline intrusion and the pattern of saline water flow. Though geochemical analysis gives accurate results at a given point, geophysical investigations generates superior results because it measures the trend of saline intrusion over a large expanse of the region and this information can be obtained at a faster rate than with the alternative techniques. Geophysical investigation provides more information faster than the drilling techniques. Subsequently, geophysical methods have become more important for saltwater intrusion monitoring.

This research, like previous work on saline water intrusion (Nowroozi et al. 1999; Nassir et al. 2000; Choudhury et al. 2001; Khalil 2006; de Franco et al. 2009; Kazakis et al. 2016; Giordano et al. 2017; Loke et al. 2017; Du et al. 2018; Shin et al. 2019), shows that resistivity imaging is a powerful tool for quantifying the extent of saline water intrusion within a coastal region in the absence of geochemical information.

The study demonstrates the applications of time-lapse two-dimensional electrical resistivity tomography and vertical electrical sounding in identifying temporal and spatial changes of saltwater intrusion in the coastal aquifer. It is recommended that Government legislations be enacted to regulate pumping rates and locations of abstraction points. The problem of salt water intrusion in Ibeno should be placed high on the priorities of the local and state governments as the presence of saline water intrusion poses a threat to the life and well-being of the community. Consistent geophysical surveys for different years will help to establish a trend and eventually predict the rate of intrusion. Ibeno has major economic significance to the country Nigeria, and this work will provide useful information to researchers working in the region.

Acknowledgements We wish to acknowledge the contributions of the project students from department of Geology and the department of Physics, Akwa Ibom State University for their assistance during the data collection. We also acknowledge with thanks, the anonymous reviewers and the editor who cojointly contributed through constructive critisms, which led to the improvement of the manuscript.

Funding No external funding was received by any author for this research.

\section{Statement on compliance with ethical standards}

Conflict of interest The authors declare that they have no conflict of interest. 
Open Access This article is licensed under a Creative Commons Attribution 4.0 International License, which permits use, sharing, adaptation, distribution and reproduction in any medium or format, as long as you give appropriate credit to the original author(s) and the source, provide a link to the Creative Commons licence, and indicate if changes were made. The images or other third party material in this article are included in the article's Creative Commons licence, unless indicated otherwise in a credit line to the material. If material is not included in the article's Creative Commons licence and your intended use is not permitted by statutory regulation or exceeds the permitted use, you will need to obtain permission directly from the copyright holder. To view a copy of this licence, visit http://creativecommons.org/licenses/by/4.0/.

\section{References}

Affiah UE, Inim IJ, Tijani MN, Ituen AO (2018) Groundwater quality assessment for drinking water using water quality index (WQI): a case sof Eastern Obolo, southeastern Nigeria. J Environ Earth Sci 8(6):12-17

Antonellini M, Mollema P, Giambastiani B, Bishop K, Caruso L, Minchio A, Pellegrini L, Sabia M, Ulazzi E, Gabbianelli G (2008) Salt water intrusion in the coastal aquifer of the southern Po Plai, Italy. Hydrogeol J. https://doi.org/10.1007/s1004 0-008-0319-9

Barker RD, Moore J (1998) The application of time-lapse electrical tomography in groundwater studies. Lead Edge 17(10):1454-1458

Barlow PM, Reichard E (2010) Saltwater intrusion in coastal regions of North America. Hydrogeol J 18:247-260

Cassiani G, Bruno V, Villa A, Fusi N, Binley AM (2006) A saline tracer test monitored via time-lapse surface electrical resistivity tomography. J Appl Geophys 59(3):244-259

Chambers JE, Loke MH, Ogilvy RD, Meldrum PI (2004) Non-invasive monitoring of DNAPL migration through a saturated porous medium using electrical impedance tomography. J Contam Hydrol 68:1-22

Choudhury K, Saha DK, Chakraborty P (2001) Geophysical study for saline water intrusion in a coastal alluvial terrain. J Appl Geophys 46(3):189-200. https://doi.org/10.1016/S0926-9851(01)00038-6

de Franco R, Biella G, Tosi L, Teatini P, Lozej A, Chiozzotto B, Giada M, Rizzetto F, Claude C, Mayer A, Bassan V, Gasparetto-Stori G (2009) Monitoring the saltwater intrusion by time lapse electrical resistivity tomography: the Chioggia test site (Venice Lagoon, Italy). J Appl Geophys 69:117-130

Du W, Peng S, Zhu G, Zhang X (2018) Aquifer variation characteristics of overlying strata in coal mining based on time-lapse apparent resistivity monitoring. In: European association of geoscientists and engineers, 2nd conference on geophysics for mineral exploration and mining, September 2018, Portugal

Edet AE (2017) Hydrogeology and groundwater evaluation of a shallow coastal aquifer, southern Akwa Ibom State (Nigeria). Appl Water Sci 7:2397-2412. https://doi.org/10.1007/s13201-016-0432-1

Edet A, Okereke C (2001a) A regional study of saltwater intrusion in southeastern Nigeria based on the analysis of geoelectrical and hydrochemical data. Environ Geol 40:1278-1289

Edet AE, Okereke CS (2001b) Monitoring seawater intrusion in the tertiary-quaternary aquifer system, Coastal Akwa Ibom area, Southeastern Nigeria-Baseline data. In: First international conference on saltwater intrusion and coastal aquifers-monitoring, modeling, and management. Essaouira, Morocco

Esu OE, Okereke CS, Aniekan AE (1999) A regional hydrostratigraphic study of Akwa Ibom State, Southeastern Nigeria. Global J Pure Appl Sci 5(1):89-96
George NJ, Ubom AI, Ibanga JI (2014) Integrated approach to investigate the effect of leachate on groundwater around the Ikot Ekpene Dumpsite in Akwa Ibom State, South-eastern Nigeria. Int J Geophys https://doi.org/10.1155/2014/174589

George NJ, Ibanga JI, Ubom AI (2015) Geoelectrohydrogeological indices of evidence of ingress of saline water into freshwater in parts of coastal aquifers of Ikot Abasi, southern Nigeria. J Afr Earth Sci 109:37-46. https://doi.org/10.1016/j.jafrearsci .2015.05.001

Giordano N, Arato A, Comina C, Mandrone G (2017) Time-lapse electrical resistivity imaging of the thermally affected zone of a Borehole Thermal Energy Storage system near Torino (Northern Italy). J Appl Geophys 140:123-134

Inim IJ, Affiah UE, Asuaiko ER, Abia UB, Tom AA (2017) Hydrogeochemical evaluation of groundwater in coastal alluvial aquifer of Akwa Ibom Southeastern Nigeria. J Coast Sci 4(2):1-8

IPCC (Intergovernmental Panel on Climate Change) (2007) Climate change 2007: synthesis report-summary for policymakers

Johansson S, Dahlin T (1996) Seepage monitoring in an earth embankment dam by repeated resistivity measurements. Eur J Environ Eng Geophys 1:229-247

Kazakis N, Pavlou A, Vargemezis G, Voudouris KS, Soulios G, Pliakas F, Tsokas G (2016) Seawater intrusion mapping using electrical resistivity tomography and hydrochemical data. An application in the coastal area of eastern Thermaikos Gulf, Greece. Sci Total Environ 543:373-387

Khalil MH (2006) Geoelectric resistivity sounding for delineating salt water intrusion in the Abu Zenima area, west Sinai, Egypt. J Geophys Eng 3(3):243-251

Kinzelbach W, Bauer P, Siegfried T, Brunner P (2003) Sustainable groundwater management-problems and scientific tools. Episodes-Newsmag. Int Union Geol Sci 26:279-284

Leroux V, Dahlin T (2006) Time-lapse resistivity investigations for imaging saltwater transport in glaciofluvial deposits. Environ Geol 49:347-358

Loke MH, Wilkinson PB, Chambers JE, Uhlemann S, Meldrum P (2017). Developments in resistivity inversion with electrode displacements for landslide monitoring. In: Association of geoscientists and engineers: 23rd meeting of environmental and engineering geophysics, September 2017, Sweden

Mahjoub H, Josefiina T, Sara B, Adil S, Luis R, Mohamed E, El Abdenabi M, Jamal S, Albert C (2017) Geophysical characterization of saltwater intrusion in a coastal aquifer: the case of Martil-Alila plain (North Morocco). J Afr Earth Sci 126:136-147

Monego M, Cassiani G, Deiana R, Putti M, Passadore G, Altissimo L (2010) A tracer test in a shallow heterogeneous aquifer monitored via time-lapse surface electrical resistivity tomography. Geophysics 75(4):61-73

Nassir S, Loke MH, Lee CY, Nawawi MNM (2000) Salt-water intrusion mapping by geoelectrical imaging surveys. Geophys Prospect 48:647-661

Nowroozi A, Horrocks SB, Henderson P (1999) Saltwater intrusion into the freshwater aquifer in the eastern shore of Virginia: a reconnaissance electrical resistivity survey. J Appl Geophys 42:1-22

Ogilvy RD, Kuras O, Meldrum PI, Wilkinson PB, Chambers JE, Sen M, Tsourlos P (2009) Monitoring saline intrusion of a coastal aquifer with automated electrical resistivity tomography. In: Near surface 2009-15th European meeting of environmental and engineering geophysics, Dublin, Ireland

Oldenborger GA, Knoll MD, Routh PS, LaBrecque DJ (2007) Timelapse ERT monitoring of an injection/withdrawal experiment in a shallow unconfined aquifer. Geophysics 72(4):177-187 
Petters SW (1989) Akwa Ibom state: physical background, soil and landuse and ecological problems. Technical report for Government of Akwa Ibom State. pp 603

Pool M, Carrera J (2010) Dynamics of negative hydraulic barriers to prevent seawater intrusion. Hydrogeol J 18:95-105

Radulescu M, Valerian C, Yang J (2007) Time-lapse electrical resistivity anomalies due to contaminant transport around landfills. Ann Geophys 50(3):453-468

Rahmstorf S (2010) A new view on sea level rise. Nature Rep Clim Change 4:44-45

Shin S, Park S, Kim J-H (2019) Time-lapse electrical resistivity tomography characterization for piping detection in earthen dam model of a sandbox. J Appl Geophys 170:103834. https://doi. org/10.1016/j.jappgeo.2019.103834

Singha K, Gorelick SM (2005) Saline tracer visualized with three dimensional electrical resistivity tomography: field-scale spatial moment analysis. Water Resour Res 41:W05023. https://doi. org/10.1029/2004WR003460

Slater L, Binley A, Versteeg R, Cassiani G, Birken R, Sandberg S (2002) A 3D ERT study of solute transport in a large experimental tank. J Appl Geophys 49:211-229

Sjödahl P, Dahlin T, Johansson S, Loke MH (2008) Resistivity monitoring for leakage and internal erosion detection at Hällby embankment dam. J Appl Geophys 65:155-164
Udom GJ, Etu-Efeotor JO, Esu EO (1999) Hydro chemical evaluation of groundwater in parts of Port Harcourt and Tai-Elemi Local Government Area, River. Glob J Pure Appl Sci 5:546-552

Udom GJ, Ushie FA, Esu EO (2002) A geochemical survey of groundwater in Khana and Gokana Local Government area of rivers State, Nigeria. J Appl Sci Environ Manag 11: 51-59.

Werner AD, Bakker M, Post VEA, Vandenbohede A, Lu C, AtaieAshtiani B, Simmons CT, Barry DA (2013) Seawater intrusion processes, investigation and management: recent advances and future challenges. Adv Water Resour 51:3-26

Ward AS, Gooseff MN, Singha K (2010) Imaging hyporheic zone solute transport using electrical resistivity. Hydrol Process 24:948-953

Xu D, Hu X, Shan C, Li R (2016) Landslide monitoring in southwestern China via time-lapse electrical resistivity tomography. J Appl Geophys 13:1-12

Publisher's Note Springer Nature remains neutral with regard to jurisdictional claims in published maps and institutional affiliations. 